Akses Online :

http://jurnal.iicet.org

Info Artikel:

\title{
Analisis pendekatan Adlerian dalam konseling kelompok untuk optimalisasi potensi diri siswa
}

\author{
Zadrian Ardi ${ }^{1}$, Neviyarni Neviyarni ${ }^{2}$, Yeni Karneli ${ }^{3}$, Netrawati Netrawati ${ }^{4}$ \\ ${ }^{1234}$ Universitas Negeri Padang
}

\begin{abstract}
Students have a variety of potentials that need to be explored and developed. The process of self-development is a necessity, which the school is an institution that is given the task of these efforts through counselors. However, various obstacles actually arise in the process throughout the range of student development. This is a tough challenge for counselors in alleviating developmental problems and optimizing the abilities and potential of students through counseling services, one of which is group counseling. The Adlerian approach is one approach in group counseling that is popular in practice. In this article, we will discuss the analysis of the contribution of values contained in the Adlerian approach that is implemented in group counseling services in order to optimize students' self-potential.
\end{abstract}

Keywords: group counseling, Adlerian approach, student's self potential

This is an open access article distributed under the Creative Commons Attribution License, which permits unrestricted use,
distribution, and reproduction in any medium, provided the original work is properly cited. C 2019 by author.

\section{PENDAHULUAN}

Sebagai periode transisi antara masa kanak-kanak dan periode dewasa, siswa yang berada pada masa remaja menghadapi berbagai perubahan-perubahan penting dalam hidupnya. Perubahan tersebut menuntut adanya penguasaan kemampuan dan keterampilan penting yang pada akhirnya akan digunakan sebagai modal dasar memasuki tahap perkembangan berikutnya (Kiefer, Alley, \& Ellerbrock, 2015; Scrimin, Moscardino, Finos, \& Mason, 2018). Fase remaja tersebut memiliki karakteristik unik yang berbeda dengan tahap perkembangan lainnya, antara lain perkembangan kemampuan nalar dan logika, kemampuan dalam merencanakan serta mengambil keputusan karir, kemampuan dalam bersosialisasi terutama dengan lawan jenis, kemampuan dalam mengelola emosi dan sikap serta kemampuan-kemampuan lain yang menuntut remaja untuk menguasainya (Bröder et al., 2017; Symonds \& Hargreaves, 2016).

Salah satu kekhasan utama pada perkembangan remaja adalah perkembangan kemampuan sosial. Kemampuan ini menjadi faktor utama yang dapat menentukan bagaimana siswa berperilaku dan berhubungan dengan orang lain pada masa dewasa. Namun demikian, berbagai permasalahan justru lebih banyak muncul dalam ranah hubungan sosial tersebut (Guérin \& Chagnon, 2017; Uceda-Maza \& Domínguez Alonso, 2017). Isu yang sering muncul pada perkembangan sosial remaja dapat berasal dari pola komunikasi, ketidakmampuan dalam menjalin hubungan sosial dengan lawan jenis secara sehat, adanya kelompok dan "klik" pada remaja yang cenderung mengarah pada perilaku maladaptif, perilaku antisosial dan permasalahan lain yang dapat menghambat potensi dan pengembangan kemampuan siswa (Chéronnet, 2015; Rojas, 2013). 
Potensi perkembangan sosial siswa pada hakikatnya menjadi perhatian dan fokus penting dalam pelayanan berbasis kesehatan mental di sekolah. Gangguan dan permasalahan terkait hubungan sosial dapat menjadi faktor penting terhambatnya pengembangan diri siswa. Kondisi permasalahan sosial siswa di sekolah tersebut menjadi tantangan bagi konselor dalam pelayanan konseling yang komprehensif (Afdal et al., 2019; Z Ardi et al., 2019; Zadrian Ardi \& Sisin, 2018; Illahi, Neviyarni, Said, \& Ardi, 2018). Konselor dituntut untuk mampu memahami kondisi permasalahan sosial siswa, baik dari segi penyebab, diagnosis, maupun prognosisnya (Annisa \& Naqiyah, 2015; Jiang, Wen, Qi, Zhang, \& Li, 2012; Ratnasari, 2017; Yakunina, Weigold, \& McCarthy, 2011). Terlebih dengan dinamika akar permasalahan yang dapat bersumber dari kondisi media disruptive dalam konteks perkembangan teknologi informasi saat ini. Kondisi ini menuntut penguasaan berbagai pendekatan yang mampu mengintervensi isu-isu pengembangan kemampuan sosial siswa perlu dimiliki konselor (Zadrian Ardi, Viola, \& Sukmawati, 2018; Suranata et al., 2018; Syahniar et al., 2018).

Analisis pendekatan yang secara langsung membahas perkembangan manusia dari sudut pandang pengembangan sosial perlu dilakukan. Salah satu pendekatan yang secara konsep dasar berfokus pada social interest adalah Adlerian (Gladding, 2017; Sonstegard \& Bitter, 2011). Pendekatan ini menekankan faktor sosial dibandingkan faktor biologis dalam menentukan perilaku individu, sehingga prediksi perilaku, perkembangan individu, perilaku maladaptive serta upaya teraputik terfokus pada pengembangan nilai-nilai sosial individu. Dengan karakteristik dan keunikan pendekatan Adlerian, maka dinilai pendekatan ini akan dapat dengan tepat dalam memberikan intervensi yang jitu dalam menangani permasalahan dan isu-isu yang berkaitan dengan perkembangan sosial siswa (Corey, 2015; Fall, Landreth, \& Berg, 2013; Sonstegard \& Bitter, 2011). Terutama penggunaan pendekatan ini dalam pelayanan konseling kelompok.

Walaupun demikian, penggunaan pendekatan ini masih perlu analisis yang mendalam. Hal ini didasarkan atas fakta bahwa sebagai besar konselor sekolah di Indonesia masih belum menerapkan basis pendekatan yang jelas dalam memberikan pelayanan konseling, terutama konseling kelompok (Afdal et al., 2019; Hidayat, Ardi, Herawati, \& Amrina, 2019; Illahi et al., 2018). Analisis tersebut hendaknya mengeksplorasi secara mendalam dan tepat mengenai potensi pendekatan ini dalam ranah penggunaannya, serta kecocokannya dengan karakter siswa di Indonesia. Artikel ini membahas kemungkinan dan analisis penerapan konseling kelompok dengan pendekatan Adlerian dalam rangka optimalisasi potensi siswa di sekolah (Hamm, Carlson, \& Erguner-Tekinalp, 2016; Wagner \& Elliott, 2014; Watts, 2013).

\section{Konsep Kunci Pendekatan Adlerian dalam Konseling Kelompok}

Pendekatan Adlerian juga dikenal sebagai pendekatan sosioteleologis, dimana pendekatan ini berfokus pada kekuatan sosial individu dalam mencapai sebuah tujuan tertentu. Secara umum, individu akan menciptakan pandangan mengenai diri dan orang lain dalam kerangka social interest (K K Meany-Walen \& Teeling, 2016; Ziomek-Daigle \& Land, 2016). Dengan adanya pandangan tersebut, individu akan berupaya dalam menetapkan tujuan jangka panjang dan jangka pendek sebagai dasar dalam motivasi diri, yang pada akhirnya akan berpengaruh pada perkembangan individu.

Kondisi kesempurnaan dalam hidup dianalogikan oleh Adler sebagai gerakan yang dipandu oleh tujuan jangka panjang (K K Meany-Walen \& Kottman, 2018; Tajabadi et al., 2018). Proses tersebut dalam rangka memenuhi pencarian hidup tentang perasaan inferioritas menuju keinginan dan motivasi untuk mencapai kondisi superior, memiliki kekuatan dan penguasaan, dan pada akhirnya akan memiliki kesempurnaan. Tentu saja kesempurnaan disini merupakan sebuah pencapaian individu dalam hidup. Dengan kata lain, pendekatan Adlerian meyakini bahwa perilaku individu ditentukan oleh proses kreatif dalam menentukan pilihan dan membuat makna yang pada akhirnya adalah untuk memenuhi tujuan hidup. Upaya gerakan menui masa depan dalam bentuk tindakan dan gaya hidup hendaklah dipandang dalam suatu pendekatan yang holistik serta lebih penting dibandingkan dengan kondisi di masa lalu (Annisa \& Naqiyah, 2015; Singh, Merchant, Skudrzyk, \& Ingene, 2012; Yakunina et al., 2011).

Dalam layanan konseling kelompok, posisi dan cara pandang terhadap manusia juga diterapkan oleh praktisi pendekatan Adlerian (Amianto et al., 2014; K K Meany-Walen, Bratton, \& Kottman, 2014; Sapp, 2016). Pemimpin kelompok dalam pendekatan ini lebih mengutamakan hubungan egaliter dengan anggota kelompok, sehingga pola ini menjadi dasar pendekatan Adlerian dalam setting kelompok. Selain itu, pemimpin kelompok berperan sebagai teladan bagi anggota kelompok dengan membawa berbagai karakteristik yang khas, antara lain kepercayaan diri, presence, memotivasi anggota kelompok, sanggup mengambil resiko, peduli, penerimaan, kemauan menjadi contoh, memiliki selera humor, mampu bekerjasama dengan anggota kelompok, memberikan dorongan positif dan mampu mengeksplorasi potensi-potensi anggota kelompok (Rosselet \& Stauffer, 2013; Young, 2012). Hal yang juga sangat penting adalah konselor harus mampu menyadari berbagai 
pertumbuhan anggota kelompok yang menjadi dasar dalam mengidentifikasi perkembangan diri masing-masing anggota.

Dengan kompleksitas pelaksanaan pelayanan konseling kelompok melalui pendekatan Adlerian tersebut, sedikitnya terdapat beberapa step dasar penerapan pendekatan ini di sekolah (Corey, 2015; Gladding, 2017; Sonstegard \& Bitter, 2011), antara lain:

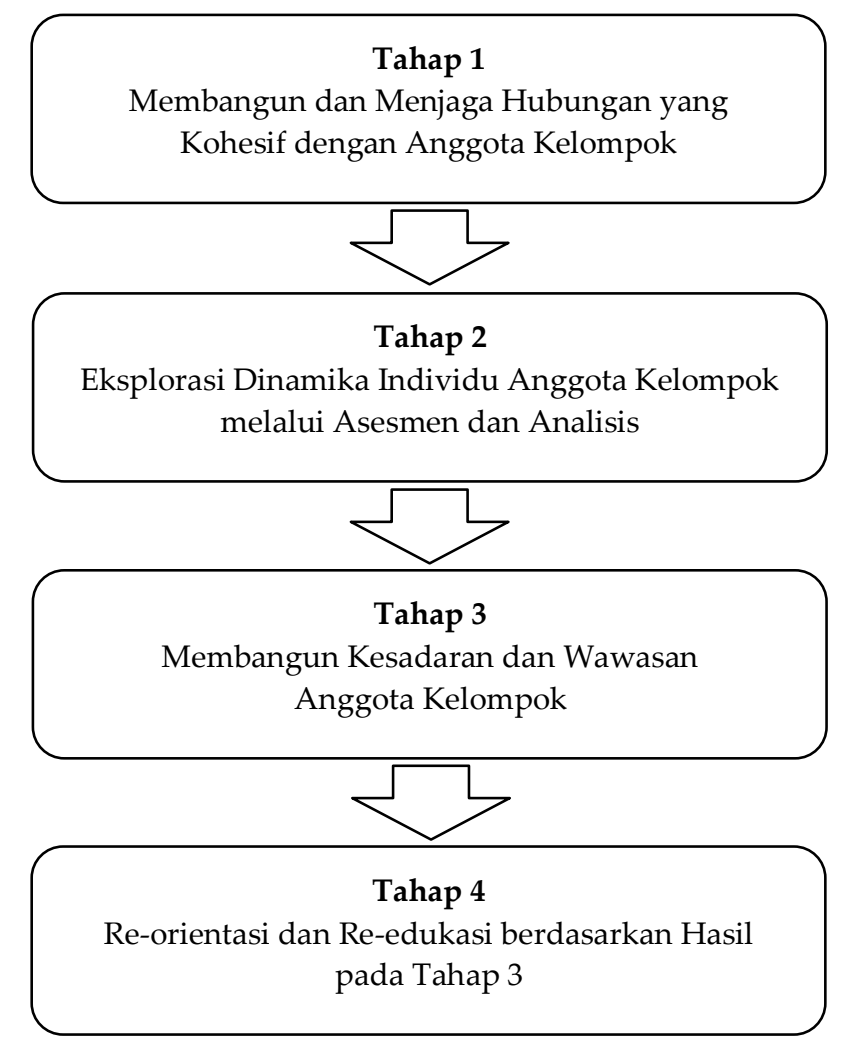

Gambar 1 Tahapan Konseling Kelompok dengan Pendekatan Adlerian

Sebagaimana dipaparkan pada Gambar 1, pada awal sesi konseling kelompok dengan pendekatan Adlerian perlu adanya upaya dalam membangun hubungan terapeutik yang solid dengan landasan kerjasama, kolaborasi, saling menghormati dan egaliter. Sesi awal tersebut pada hakikatnya berfungsi sebagai fondasi yang akan menentukan sukses atau tidaknya sesi-sesi berikutnya.

Pada tahap kedua, fokus kegiatan konseling kelompok hendaknya beralih pada pemahaman gaya hidup (life style) masing-masing anggota kelompok (Fall et al., 2013; Mosak \& Maniacci, 2013). Analisis tersebut berhubungan dengan bagaimana gaya hidup dapat mempengaruhi individu dalam setiap tugas kehidupan yang dijalaninya. Hal ini juga berkaitan dengan bagaimana individu memaknai identitas budaya yang ada pada dirinya dan mempengaruhi setiap sisi kehidupan anggota kelompok. Pada tahap berikutnya dalam proses konseling kelompok dengan pendekatan ini, perlu adanya upaya membawa suatu perubahan dalam bentuk kesadaran dan wawasan yang dijadikan dasar dari suatu perubahan dalam diri klien anggota kelompok. Sedangkan produk akhir dari proses konseling kelompok dengan pendekatan Adlerian adalah proses re-orientasi dan re-edukasi. Proses re-orientasi berkenaan dengan bagaimana pemimpin kelompok mengajak anggota kelompok dalam menganalisis berbagai kepercayaan, tujuan serta gaya hidup yang salah, serta mencari berbagai pertimbangan gaya hidup, tujuan dan alternatif lain yang ditetapkan atas dasar wawasan, yang telah diperoleh anggota kelompok selama sesi berlangsung (Duba Sauerheber \& Bitter, 2013; Hamm et al., 2016; Jiang et al., 2012; Yakunina et al., 2011).

\section{Evaluasi Implementasi Pendekatan Adlerian di Sekolah}

Pendekatan Adlerian dalam sesi konseling kelompok memegang peranan dalam melihat hal-hal berharga dalam hidup, dimana memori mengenai hal tersebut berkaitan dengan apa yang paling dihargai dalam hidup sehingga menjadi sebuah tujuan yang memberikan motivasi dalam mencapainya melalui serangkaian gaya 
hidup. Setiap keputusan dan tujuan yang telah ditetapkan di masa lalu akan memberikan kontribusi dalam menentukan sikap dan berbagai hal yang perlu diantisipasi di masa depan (Corey, 2015). Dapat dikatakan pendekatan ini akan memberikan kemampuan analisis dan intervensi terhadap kondisi anggota kelompok secara menyeluruh/holistik mencakup seluruh pengalaman-pengalaman individu.

Kemampuan penerapan pendekatan ini dalam situasi kelompok pada beragam populasi menjadi salah satu kekuatan penting, terutama dalam penerapannya pada siswa atau setting pendidikan (Zadrian Ardi, 2017a, 2017b; Daharnis \& Ardi, 2017; Hidayat, Herawati, Syahmaidi, Hidayati, \& Ardi, 2018; Yendi, Ardi, \& Ifdil, 2014). Berbagai riset terkait penerapan pendekatan Adlerian dalam sesi konseling kelompok menunjukkan bahwa penekanan faktor sosial yang menjadi dasar pendekatan ini memiliki tingkat keberhasilan tinggi pada berbagai kelompok sasaran seperti orangtua, kelompok guru, keluarga dan siswa. Dengan dasar teori fenomenologis, optimis dan holistik berdasarkan prinsip-prinsip sosial yang menjadi dasar pendekatan ini, pendekatan Adlerian menjadi kongruen dengan berbagai pendekatan lain bahkan pendekatan kontemporer, seperti Solution Focused Brief Counseling (SFBC), Rational Emotive Behavior Therapy (REBT), terapi gestalt, terapi eksistensial, Client-Centered Therapy dan banyak pendekatan lain (Corey, 2015; Sonstegard \& Bitter, 2011).

Peluang besar pada pendekatan ini menjadi kekuatan utama yang memungkinkan adanya intervensi yang menyeluruh terhadap kondisi permasalahan yang dialami siswa (Corey, 2015; Kristin K Meany-Walen, Bullis, Kottman, \& Dillman Taylor, 2015; Sonstegard \& Bitter, 2011). Terdapat banyak relevansi pendekatan ini dengan kebutuhan siswa di sekolah dengan kompleksitas masalah yang dialami. Remaja pada umumnya mengalami berbagai perasaan putus asa yang mendalam, dimana dengan menggunakan prinsip-prinsip pendekatan ini maka akan memungkinkan masing-masing anggota mengungkapkan diri dan keputusasaan tersebut dan merasa bahwa siswa yang bermasalah tersebut tidak sendirian. Dengan menggunakan empat tahap dalam pendekatan konseling melalui teori Adlerian tersebut akan memungkinkan siswa yang kurang memiliki tujuan, sehingga dengan adanya proses reorientasi dan re-edukasi akan menjadikan siswa dapat menentukan tujuan baru yang akan dicapai dalam hidup sehingga akan mengubah paradigma dan gaya hidupnya. Potensi besar tersebut juga cocok untuk diterapkan dalam rangka optimalisasi potensi siswa (Corey, 2015).

\section{KESIMPULAN}

Sebagai sebuah pendekatan dalam sesi konseling kelompok yang menekankan pada penetapan tujuan hidup sehingga akan mempengaruhi perilaku dan proses pengambilan keputusan individu, pendekatan Adlerian diasumsikan sesuai untuk diterapkan dalam rangka optimalisasi potensi diri siswa di sekolah. Hal ini didasarkan atas kemampuan pendekatan ini dalam melakukan reorientasi dan re-edukasi tujuan hidup siswa yang pada awalnya kurang jelas menjadi lebih terarah, sehingga dengan demikian upaya dalam optimalisasi potensi diri akan dapat tercapai. Selain itu, capaian optimalisasi tersebut juga dapat terukur dengan jelas melalui rangkaian sesi konseling kelompok.

\section{DAFTAR RUJUKAN}

Afdal, A., Alizamar, A., Ifdil, I., Ardi, Z., Sukmawati, I., Zikra, Z., ... Hariyani, H. (2019). An Analysis of Phubbing Behaviour: Preliminary research from counseling perspective. In International Conference on Educational Sciences and Teacher Profession (ICETeP 2018). Atlantis Press.

Amianto, F., Bertorello, A., Spalatro, A., Milazzo, M., Signa, C., Cavarero, S., ... Fassino, S. (2014). Adlerian parental counseling in eating disorders: Preliminary data of a controlled clinical trial. Eating and Weight Disorders, 19(3), 303-314. https://doi.org/10.1007/s40519-013-0079-y

Annisa, R. A. R. W., \& Naqiyah, N. (2015). The Application of Adlerian Group Counseling To Increase the Self-Adjustment. Jurnal Bimbingan Dan Konseling.

Ardi, Z. (2017a). Unsuitable Majoring: Does the Reorientation Would Help the Student for Revitalize Learning Activities? In Proceedings of the 9th International Conference for Science Educators and Teachers (ICSET 2017). Paris, France: Atlantis Press. https://doi.org/10.2991/icset-17.2017.69

Ardi, Z. (2017b). Unsuitable Majoring: Does the Reorientation Would Help the Student for Revitalize Learning Activities? In 9th International Conference for Science Educators and Teachers (ICSET 2017). Atlantis Press. https://doi.org/10.2991/icset-17.2017.69

Ardi, Z., Rangka, I. B., Ifdil, I., Suranata, K., Azhar, Z., Daharnis, D., ... Alizamar, A. (2019). Exploring the elementary students learning difficulties risks on mathematics based on students mathematic anxiety, mathematics self-efficacy and value beliefs using rasch measurement. In Journal of Physics: Conference Series (Vol. 1157, p. 32095). IOP Publishing. 
Ardi, Z., \& Sisin, M. (2018). The Contribution of Assertive Technique Behavioral Counseling to Minimize the Juvenile Delinquency Behavior. Jurnal Konseling Dan Pendidikan, 6(2), 67-77.

Ardi, Z., Viola, K., \& Sukmawati, I. (2018). An Analysis of Internet Abuses Impact on Children's Moral Development. JPPI (Jurnal Penelitian Pendidikan Indonesia), 4(1), 44-50. https://doi.org/10.29210/02018192

Bröder, J., Okan, O., Bauer, U., Bruland, D., Schlupp, S., Bollweg, T. M., ... Pinheiro, P. (2017). Health literacy in childhood and youth: A systematic review of definitions and models. BMC Public Health, 17(1). https://doi.org/10.1186/s12889-017-4267-y

Chéronnet, H. (2015). Performance de l'action publique et carrières de jeunes délinquants. Dilemas, (1), 299326. Retrieved from https://www.scopus.com/inward/record.uri?eid=2-s2.084953299688\&partnerID=40\&md5=f7cca94a3217108c1f7e2fc4d1cc71ad

Corey, G. (2015). Theory and practice of counseling and psychotherapy. Nelson Education.

Daharnis, D., \& Ardi, Z. (2017). Optimizing the Counselors' Role in Senior High School and Higher Education.

Duba Sauerheber, J., \& Bitter, J. R. (2013). An Adlerian Approach in Premarital Counseling with Religious Couples. Journal of Individual Psychology, 69(4).

Fall, K. A., Landreth, G. L., \& Berg, R. C. (2013). Group counseling: Concepts and procedures. Routledge.

Gladding, S. T. (2017). The counseling dictionary. John Wiley \& Sons.

Guérin, A., \& Chagnon, J. Y. (2017). The being female in the use of violent acts by teenage offenders Neuropsychiatrie de l'Enfance et de l'Adolescence, 65(2), 83-91. https://doi.org/10.1016/j.neurenf.2016.11.006

Hamm, J. S., Carlson, J., \& Erguner-Tekinalp, B. (2016). Adlerian-based positive group counseling interventions with emotionally troubled youth. The Journal of Individual Psychology, 72(4), 254-272.

Hidayat, H., Ardi, Z., Herawati, S., \& Amrina, Z. (2019). The Contribution of Internal Locus of Control and Self-Concept to Career Maturity in Vocational Higher Education. KnE Social Sciences, 3(15), 234-248.

Hidayat, H., Herawati, S., Syahmaidi, E., Hidayati, A., \& Ardi, Z. (2018). Designing of technopreneurship scientific learning framework in vocational-based higher education in Indonesia. International Journal of Engineering and Technology(UAE), 7(4), 123-127. https://doi.org/10.14419/ijet.v7i4.9.20632

Illahi, U., Neviyarni, N., Said, A., \& Ardi, Z. (2018). Hubungan antara kecerdasan emosi dengan perilaku agresif remaja dan implikasinya dalam bimbingan dan konseling. JRTI (Jurnal Riset Tindakan Indonesia), $3(2), 68-74$.

Jiang, Y. Q., Wen, H. G., Qi, L. Q., Zhang, X. X., \& Li, Y. (2012). Salt minerals and their genesis of the Permian Fengcheng Formation in Urho area, Junggar Basin. Kuangwu Yanshi/ Journal of Mineralogy and Petrology, 32(2), 105-114. https://doi.org/10.1002/pits

Kiefer, S. M., Alley, K. M., \& Ellerbrock, C. R. (2015). Teacher and Peer Support for Young Adolescents' Motivation, Engagement, and School Belonging. RMLE Online, 38(8), 1-18. https://doi.org/10.1080/19404476.2015.11641184

Meany-Walen, K. K., Bratton, S. C., \& Kottman, T. (2014). Effects of adlerian play therapy on reducing students' disruptive behaviors. Journal of Counseling and Development, 92(1), 47-56. https://doi.org/10.1002/j.1556-6676.2014.00129.x

Meany-Walen, K. K., Bullis, Q., Kottman, T., \& Dillman Taylor, D. (2015). Group Adlerian play therapy with children with off-task behaviors. The Journal for Specialists in Group Work, 40(3), 294-314.

Meany-Walen, K. K., \& Kottman, T. (2018). Group Adlerian Play Therapy. International Journal of Play Therapy. American Psychological Association Inc. https://doi.org/10.1037/pla0000079

Meany-Walen, K. K., \& Teeling, S. (2016). Adlerian play therapy with students with externalizing behaviors and poor social skills. International Journal of Play Therapy, 25(2), 64-77. https://doi.org/10.1037/pla0000022

Mosak, H., \& Maniacci, M. (2013). Primer of Adlerian psychology: The analytic-behavioural-cognitive psychology of Alfred Adler. Routledge.

Ratnasari, D. (2017). Spitting in The Soup: Disain Intervensi dalam Konseling untuk Mereduksi Perilaku Maladaptif pada Remaja. TERAPUTIK: Jurnal Bimbingan Dan Konseling, 1(1), 78. https://doi.org/10.26539/115

Rojas, N. (2013). [The mental anormality in the youth deliquency]. . Vertex (Buenos Aires, Argentina), 24(108), 151-154. Retrieved from https://www.scopus.com/inward/record.uri?eid=2-s2.084892886610\&partnerID=40\&md5=bfaa584fe153261d4285cc50d35b080e

Rosselet, J. G., \& Stauffer, S. D. (2013). Using group role-playing games with gifted children and adolescents: A psychosocial intervention model. International Journal of Play Therapy, 22(4), 173-192. https://doi.org/10.1037/a0034557

Sapp, M. (2016). Hypnosis and postmodernism: Multicultural applications. Sleep and Hypnosis, 18(1), 19-25. https://doi.org/10.5350/Sleep.Hypn.2016.180104 
Scrimin, S., Moscardino, U., Finos, L., \& Mason, L. (2018). Effects of Psychophysiological Reactivity to a School-Related Stressor and Temperament on Early Adolescents' Academic Performance. Journal of Early Adolescence. University of Padova, Italy: SAGE Publications Inc. https://doi.org/10.1177/0272431618797008

Singh, A. A., Merchant, N., Skudrzyk, B., \& Ingene, D. (2012). Association for Specialists in Group Work: Multicultural and Social Justice Competence Principles for Group Workers. Journal for Specialists in Group Work, 37(4), 312-325. https://doi.org/10.1080/01933922.2012.721482

Sonstegard, M. A., \& Bitter, J. R. (2011). Adlerian group counseling: Step by step. New York: Taylor \& Francis Books, Inc.

Suranata, K., Rangka, I. B., Ifdil, I., Ardi, Z., Susiani, K., Prasetyaningtyas, W. E., ... Rahim, R. (2018). Diagnosis of students zone proximal development on math design instruction: A Rasch analysis. In 2018 Workshop on Multidisciplinary and Its Applications: Applied Mathematics, Computer Science, Information Systems, and Information Technology, WMA-Mathcomtech 2018 (Vol. 1114). Institute of Physics Publishing. https://doi.org/10.1088/1742-6596/1114/1/012034

Syahniar, S., Maysitoh, M., Ifdil, I., Ardi, Z., Yendi, F. M., Rangka, I. B., ... Churnia, E. (2018). Social media fear of missing out: Psychometrics evaluation based on Indonesian evidence. In 2018 Workshop on Multidisciplinary and Its Applications: Applied Mathematics, Computer Science, Information Systems, and Information Technology, WMA-Mathcomtech 2018 (Vol. 1114). Universitas Negeri Padang, Padang Sumatera Barat, Indonesia: Institute of Physics Publishing. https://doi.org/10.1088/17426596/1114/1/012095

Symonds, J., \& Hargreaves, L. (2016). Emotional and Motivational Engagement at School Transition: A Qualitative Stage-Environment Fit Study. Journal of Early Adolescence, 36(1), 54-85. https://doi.org/10.1177/0272431614556348

Tajabadi, F., Ahmadi, A., Forouzi, M., Ahmadi, Z. S., Jahani, Y., Najafi, K., \& Bafghi, M. J. A. (2018). The effect of Adlerian group counseling on the level of assertiveness among midwifery students in clinical setting. Indian Journal of Forensic Medicine and Toxicology, 12(2), 216-221. https://doi.org/10.5958/0973-9130.2018.00105.6

Uceda-Maza, F. X., \& Domínguez Alonso, J. (2017). The link between vulnerability and social exclusion and criminal trajectories. An association study . Psychosocial Intervention, 26(1), 29-37. https://doi.org/10.1016/j.psi.2016.07.003

Wagner, H. H., \& Elliott, A. (2014). Adlerian Adventure-Based Counseling to Enhance Self-Esteem in School Children. Journal of School Counseling, 12(14), n14.

Watts, R. E. (2013). Adlerian counseling. The Handbook of Educational Theories, 459-472.

Yakunina, E. S., Weigold, I. K., \& McCarthy, A. S. (2011). Group counseling with international students: Practical, ethical, and cultural considerations. Journal of College Student Psychotherapy, 25(1), 67-78. https://doi.org/10.1080/87568225.2011.532672

Yendi, F. M., Ardi, Z., \& Ifdil, I. (2014). Pelayanan Konseling untuk Remaja Putri Usia Pernikahan. Jurnal Konseling Dan Pendidikan, 1(2), 109-114. Retrieved from http://www.ingentaconnect.com/content/doaj/23376740/2014/00000001/00000002/art00004

Young, M. A. (2012). Purpose-Driven Conversations: An Interview With James Bitter. The Family Journal, 20(2), 200-204. https://doi.org/10.1177/1066480712438521

Ziomek-Daigle, J., \& Land, C. (2016). Adlerian-Based Interventions to Reduce Bullying and Interpersonal Violence in School Settings. Journal of Creativity in Mental Health, 11(3-4), 298-310. https://doi.org/10.1080/15401383.2016.1217182 